\title{
DRUG DISCRIMINATION UNDER A CONCURRENT SCHEDULE
}

\author{
Samuel H. SNOdgrass and D. E. McMillan
}

UNIVERSITY OF ARKANSAS FOR MEDICAL SCIENCES

\begin{abstract}
Three pigeons were trained to discriminate a $5.0 \mathrm{mg} / \mathrm{kg}$ dose of pentobarbital from saline under a two-key concurrent schedule with responding on the key associated with the presession injection, under both stimulus conditions, producing four times as many reinforcers as responding on the other key. This concurrent schedule resulted in approximately $70 \%$ responding to the higher reinforcement key under the pentobarbital stimulus and approximately $30 \%$ responding to that key under the saline stimulus. During testing, then, the pigeons were able to dose-dependently emit higher $(>70 \%)$ or lower $(<30 \%)$ values than were established under the control conditions. Doseresponse curves were determined for pentobarbital (twice), methamphetamine, phencyclidine, chlordiazepoxide, and the combination of pentobarbital and the barbiturate antagonist bemegride. The results obtained with pentobarbital and chlordiazepoxide showed that, as the dose increased, pentobarbital-appropriate responding also increased. Methamphetamine produced relatively flat dose-response curves, whereas phencyclidine administration produced inconsistent effects on responding. The combination of the training dose of pentobarbital with increasing doses of bemegride produced a decrease in pentobarbital-appropriate responding. The results also showed that the doseresponse curves for pentobarbital and chlordiazepoxide, instead of being all or none, were graded functions of the drug dose.
\end{abstract}

Key words: drug discrimination, concurrent schedule, matching law, graded versus quantal doseresponse curve, pentobarbital, key peck, pigeons

Research with the drug discrimination procedure has typically been directed towards understanding the pharmacology of drug stimuli (Young \& Sannerud, 1991). Thus, although research on the effects of procedural variables has established their importance (e.g., Colpaert, 1987; Holloway \& Gauvin, 1989; Overton, 1988), these variables have received comparatively little attention in studies of drug discrimination (Branch, 1991). One of the most important of these procedural variables is the schedule of reinforcement that maintains responding (Snodgrass \& McMillan, 1991). Although it has been reported that differences in the rate of reinforcement between schedules can bias drug discrimination responding (Koek \& Slangen, 1982; McMillan \& Wenger, 1984), and that different reinforcement schedules can produce reliable and valid drug discrimination data (Overton, 1979; Stolerman, 1989), there has been relatively little research concerning schedule control and the drug discrimination procedure.

Our thanks go to Susan Passwaters for her assistance in conducting this experiment. This research was supported by NIDA Grant DA02251 to D. E. McMillan.

Send reprint requests to D. E. McMillan, Department of Pharmacology and Toxicology, Slot 611, University of Arkansas for Medical Sciences, 4301 West Markham St., Little Rock, Arkansas 72205.
One reason for the lack of research on schedule control and drug discrimination may be the dominance of the two-key fixedratio (FR) procedure in drug discrimination experiments (Colpaert, 1986; Overton, 1988). Although many variants of the FR schedule procedure have been used in drug discrimination experiments (see Overton, 1984), under the basic training procedure a subject is exposed to a choice between two response keys, with responding on one key reinforced under an FR schedule after drug administration and responding on the other key reinforced under an identical FR schedule after vehicle administration. Responses on the drug key after vehicle administration, or responses on the vehicle key after drug administration, never produce the reinforcer (Colpaert, 1985). According to Colpaert (1985, 1987), because responses on the drug key are reinforced only in the presence of the training drug stimulus and responses on the vehicle key are reinforced only in the absence of the training drug stimulus, an all-or-none, or quantal, relationship is established between the presence and absence of the drug stimulus and the reinforced response. Colpaert (1991) states that, because of this quantal relationship, the dependent variable in drug discrimination studies can be viewed as 
representing the categories of stimulus present and stimulus absent (i.e., the dependent variable should be viewed as a binary variable measured on a nominal scale).

Quantal data are obtained, as Stolerman (1991) has noted, primarily under FR schedules. Thus, although the amount of drug discrimination research that directly touches on this question is relatively small, there is evidence that not all reinforcement schedules produce quantal dose-response curves (Holloway \& Gauvin, 1989; Stolerman, 1991). Some of this evidence comes from investigations of the differences between FR and fixed-interval (FI) schedules on the control of drug discrimination behavior. Massey, McMillan, and Wessinger (1992) have shown that individual pigeons produced quantal dose-response curves under an FR drug discrimination procedure. A separate group of pigeons that responded under an FI drug discrimination procedure, however, produced individual dose-response curves that were continuous functions of the drug dose. In an earlier study, the effects of a multiple FI FR schedule on the form of individual dose-response curves were determined in rats (Snodgrass \& McMillan, 1991). Under the FR component the rats produced quantal doseresponse curves, whereas under the FI component continuous dose-response curves were produced. Thus, the form of the dependent variable was determined by the schedule of reinforcement that controlled responding. Whether the dependent variable was, in fact, continuous, but forced into the quantal form by the FR schedule, is not known.

Whether a quantal or continuous generalization gradient occurs may, therefore, depend on the contingencies of reinforcement. In the present study, a pentobarbital discrimination was established with responding maintained under a concurrent variable-interval variable-interval (VI VI) schedule. Typically, a drug discrimination is established by reinforcing "correct" responses and by extinguishing "incorrect" responses under the appropriate training stimuli. Thus, the discrimination is established under quantal reinforcement contingencies (Colpaert, 1985, 1987). The goal in the present study was to establish the drug discrimination under a concurrent VI VI schedule using relative reinforcement contingencies. Therefore, during training, responses on both keys were reinforced in the presence and absence of the training drug. The programmed rate of reinforcement, however, differed between the two responses such that, after training-drug administration, the schedule associated with one key (pentobarbital key) provided a 4:1 ratio of reinforcers in comparison to the schedule associated with the other key (saline key). After saline administration, the schedule associated with the saline key was programmed to provide a 4:1 ratio of reinforcers in comparison to the schedule associated with the pentobarbital key. Thus, the reinforcement contingencies of the present study, instead of being quantal, were graded.

Although pigeons have been trained to discriminate between exteroceptive stimuli under relative reinforcement contingencies in studies of matching and signal detection (cf. Davison \& McCarthy, 1980, 1988; Logue, 1983; Nevin, Jenkins, Whittaker, \& Yarensky, 1982), it was not known if drug stimuli would control responding under contingencies of relative reinforcement. If a drug discrimination was successfully established under this concurrent schedule, a further goal of the study would be to determine the shape of the dose-response curves of the individual pigeons.

Pentobarbital was chosen as the training drug because rapid and stable discriminations can be established with this drug (e.g., Snodgrass \& McMillan, 1991). Other drugs used to determine the specificity of the discriminative stimulus effects of pentobarbital were phencyclidine (PCP), chlordiazepoxide, and methamphetamine. These drugs were selected because they each produce different levels of substitution for pentobarbital. PCP typically substitutes partially for pentobarbital, but only occasionally does a subject respond as if PCP were pentobarbital (Snodgrass \& McMillan, 1991; Willetts \& Balster, 1989). Chlordiazepoxide and other benzodiazepines have been reported to substitute for pentobarbital (Barry \& Krimmer, 1978; Herling, Valentino, \& Winger, 1980). Methamphetamine was not expected to substitute for pentobarbital. The antagonism of the discriminative effects of pentobarbital by the administration of bemegride (Herling et al., 1980; Herling \& Winger, 1981) was also determined under the concurrent-schedule procedure. Thus, substitution tests were con- 
ducted with drugs that were expected to substitute completely, partially, and not at all with pentobarbital.

\section{METHOD}

Subjects

Three adult male White Carneau pigeons served as subjects. The pigeons were individually housed in a large colony room with continuous access to grit and water in the home cage. After $100 \%$ body weights were determined, the pigeons were reduced to, and maintained at, approximately $80 \%$ of these weights for the duration of the study. Supplemental feedings of mixed grain were provided as necessary to maintain the $80 \%$ body weights. The pigeons received supplemental vitamins in the drinking water. A light-dark cycle with lights on at 7:00 a.m. and lights off at 7:00 p.m. was in effect in the colony room.

\section{Apparatus}

The apparatus consisted of a Gerbrands sound-attenuating enclosure in which a Gerbrands three-key pigeon chamber (Model G5610-A) was housed. The three response keys were centered in a horizontal row on the front panel. During the session the left key was transilluminated by a green light and the right key was transilluminated by a red light. The center key remained darkened and was not operative. A square opening was located in the center of the front panel and allowed access to mixed grain during periods of reinforcement. The operant chamber contained two 28-V houselights that were centered in the back quarter of the Plexiglas chamber roof. White noise and circulation of air were provided by a fan located in the rear wall of the sound-attenuating enclosure.

Initially, the behavioral contingencies were controlled by, and the responding of the subjects was recorded by, a TRS- $80^{\circledR}$ Model III microcomputer interfaced with the operant chamber by a Microcomputer Interface $\mathrm{II}^{\circledR}$ and later with a Gateway 2000 microcomputer with a MedState ${ }^{\circledR}$ interface. The programming of the behavioral contingencies was accomplished with the MedState 2.0 programming language. All of the microcomputer and interfacing equipment was located in a room adjacent to the one that contained the operant equipment.

\section{Procedure}

The pigeons were experimentally naive at the beginning of the study. After they had been reduced to $80 \%$ of their free-feeding weights, they were taught to key peck by an autoshaping procedure. During initial training the left key, which was always transilluminated by a green light when it was operative, was associated with the reinforcer for 25 autoshaping trials. The left keylight was then extinguished and the right key, which was transilluminated with red light when it was operative, was associated with the reinforcer for 25 autoshaping trials. Next, only the left key was operative and each left key response produced the reinforcer (4-s access to mixed grain). Subsequently, the left keylight was extinguished and each response on the right key produced the reinforcer. When the pigeons had earned the 50 reinforcers in one session of left-key responding and one session of right-key responding, the next training phase was initiated.

Unless otherwise indicated, prior to each subsequent training and test session, the pigeons were administered the drug or vehicle and placed in the darkened operant chamber for a 10-min presession period. During this presession the chamber lights were extinguished and the keys were inoperative. Under normal training and test conditions, when the presession ended, both keys were transilluminated, the houselights were illuminated, and the behavioral contingencies were initiated. For the first few training sessions, however, only the left or the right key was transilluminated depending upon whether the training drug $(5.0 \mathrm{mg} / \mathrm{kg}$ pentobarbital) or the vehicle $(1.0 \mathrm{ml} / \mathrm{kg}$ physiologic saline) was administered. For Pigeon P257, responses on the right key (red key) were reinforced after pentobarbital administration and responses on the left key (green key) were reinforced after saline administration. For P259 and P260, these reinforcement contingencies were reversed. After each pigeon had earned 50 reinforcers under the continuous reinforcement schedule during both a pentobarbital and a saline stimulus session, discrimination training was initiated.

Under the discrimination training procedure, both the left and right keys were transilluminated, and responding was reinforced 
by 4-s access to mixed grain under a concurrent VI VI schedule. The VI schedules were developed according to the method of Fleshler and Hoffman (1962). This method produces a VI schedule such that the local probability of reinforcement (i.e., the probability of reinforcement per unit time) remains relatively constant (Catania \& Reynolds, 1968). For Pigeon P257, the concurrent VI VI schedule was programmed to allow the bird to earn four times as many reinforcers on the right key as on the left key, after administration of the training drug. After vehicle administration, P257 could earn four times as many reinforcers on the left key as on the right key. For P259 and P260, the reinforcement contingencies after administration of the training drug and saline were reversed. The training sessions were $40 \mathrm{~min}$ in length, and the initial concurrent VI VI training values were $15 \mathrm{~s}$ and $60 \mathrm{~s}$. The pigeons responded under this concurrent VI 15-s VI 60-s schedule for six sessions-three saline sessions and three pentobarbital sessions in a single alternation order. The schedule values were then increased to a concurrent VI 30-s VI 120-s schedule for eight sessions. For these sessions the administration of saline and pentobarbital was alternated so that each was in effect for four sessions.

The schedule values during the subsequent training sessions were a concurrent VI 60-s VI 240-s schedule or a concurrent VI 240-s VI 60$s$ schedule of reinforcement. Which of the concurrent schedules was in effect depended upon whether pentobarbital or saline had been administered. Responding was maintained under these concurrent schedules for the duration of the study, with the exception of control and test sessions. Each concurrent VI schedule functioned independently so that reinforcement availability under one VI schedule had no effect on reinforcement availability under the other VI schedule. A 3$s$ changeover delay (COD) was programmed to occur when a pigeon switched its responding from one VI schedule to the other VI schedule. During this COD, a reinforcer could not be delivered. Thus, a superstitious association between a changeover response and reinforcer delivery was avoided (Catania, 1966).

Training sessions were conducted 6 days per week, Sunday through Friday. During this training phase, pentobarbital and saline were administered according to a double alternation sequence (D D S S D D S, etc.) that continued until the initiation of substitution testing. Prior to the initiation of substitution testing, two stability criteria had to be met. Under one criterion the pigeons had to respond predominantly $(\geq 51 \%)$ on the appropriate key for 10 consecutive sessions, five each of pentobarbital and saline. Under the other criterion, the percentage of responding on the appropriate key had to be within \pm 1 standard deviation of the mean of the previous five sessions. These criteria had to be met for both pentobarbital and saline administration prior to the initiation of substitution testing.

During this substitution phase, test sessions were typically conducted twice a week, on Tuesdays and Fridays, with training sessions continuing on the remaining 4 days. Administration of pentobarbital and saline was changed from a double to a single alternation sequence for the training sessions of the substitution phase. Prior to each test session, a pentobarbital and saline training session was conducted. If, prior to the test session, the proportion of responding on the key appropriate for the stimulus condition was $51 \%$ or greater after both pentobarbital and saline administration, then substitution testing was allowed to proceed. If the proportion was less than $51 \%$ under either the pentobarbital or saline training session, then training sessions continued until the criterion had been met.

The procedure used during substitution tests was identical to the procedure used during training sessions with the exception of the concurrent VI VI schedule values. For test sessions, a concurrent VI 150-s VI 150-s schedule of reinforcement was in effect. This 150-s VI schedule value was halfway between the 60-s and the 240-s VI values. The schedule also had the advantage that none of the pigeons had experienced this reinforcement rate prior to the test sessions. The pentobarbital and saline training stimuli were administered to the pigeons under the concurrent VI 150-s VI 150-s schedule prior to the initiation of each dose-response curve and after the dose-response data were collected. These sessions were designated as control sessions and measured the effect of the schedule used during 
substitution tests on the stability of the stimulus control of behavior.

Substitution tests were conducted in single test sessions on different days for each dose for each pigeon. The training, control, and substitution test sessions were $40 \mathrm{~min}$ in length, and data were collected for the entire session. These data included the number of changeovers, the number of responses under each schedule, the number of reinforcers earned under each schedule, and the session time and local time. The number of changeovers was defined as the number of responses that initiated a switch from one to the other response key. The local time was defined as the duration of time the pigeon allocated to each of the VI schedules minus the total reinforcement time under that schedule. Time allocation was determined by measuring the duration of time the pigeon spent responding on each key beginning with the changeover response and ending with the subsequent changeover response. The session time was the sum of the local times. From these data, two other measures were derived. One measure was the percentage of responding on the pentobarbital key. The pentobarbital key was defined as the key associated with the VI 60-s schedule after the administration of pentobarbital during the training sessions. The saline key was defined as the key associated with the VI 60-s schedule after administration of saline during the training sessions. The percentage of responding on the pentobarbital key was defined as the number of responses emitted on the pentobarbital key divided by the total number of responses emitted on both the saline and pentobarbital keys. The second measure was the percentage of time allocated to responding on the pentobarbital key and was defined as the pentobarbital key local time divided by the session time. Data obtained under each of the test drugs are presented in the Appendix. These data include the number of responses on each of the keys, the number of changeovers, the number of reinforcers earned by responding on each key, and the duration of time allocated to responding on each key. If a pigeon earned less than half of the possible number of programmed reinforcers, the data obtained at that dose are not included in the Results or the Appendix.

Injections were administered in the breast muscle of the pigeon, in a volume of $1 \mathrm{ml} /$ $\mathrm{kg}$ of body weight. With the exception of the bemegride experiments, all injections were administered $10 \mathrm{~min}$ prior to session initiation. Bemegride was administered 15 min prior to session initiation in one breast muscle, and the administration of the pentobarbital $(5.0 \mathrm{mg} / \mathrm{kg}$ ) or the saline training stimulus was administered $5 \mathrm{~min}$ later in the other breast muscle. In the bemegride experiments, saline administration occurred $15 \mathrm{~min}$ prior to session initiation during the training and control sessions, and either the training dose of pentobarbital or saline was administered 5 min later. The drugs and doses used in this study included sodium pentobarbital, bemegride, and chlordiazepoxide hydrochloride, each administered at the doses of 1.0 , $3.0,5.6,7.8,10.0$, and $13.0 \mathrm{mg} / \mathrm{kg}$. The other two drugs were methamphetamine hydrochloride at doses of $0.3,1.0,1.8$, and $3.0 \mathrm{mg}$ / $\mathrm{kg}$ and phencyclidine hydrochloride administered at $0.1,0.3,0.56,1.0$, and $1.8 \mathrm{mg} / \mathrm{kg}$. All of the drugs were dissolved in physiologic saline in a volume of $1 \mathrm{ml} / \mathrm{kg}$. The appropriate doses of bemegride were prepared on each test day.

\section{RESULTS}

The number of training sessions under the concurrent VI VI schedule prior to meeting the stability requirements was 64 for Pigeon P257, 79 for P259, and 54 for P260. Administration of pentobarbital caused more variability in responding than did the administration of saline, so it was more difficult to attain stability under the pentobarbital training condition.

Table 1 shows the mean number of responses, mean number of reinforcers earned, and mean time allocated on the drug and saline keys for each pigeon over the last five pentobarbital and the last five saline training sessions prior to the initiation of testing. Under the pentobarbital training sessions, each of the pigeons emitted a slightly higher total number of responses compared to the total number of responses emitted after saline administration. The number of reinforcers obtained by each pigeon under the two training conditions, however, was nearly identical. Thus, the training dose of pentobarbital did not suppress responding, nor did it decrease 
Table 1

Individual subject means of the number of responses, number of reinforcers earned, and the amount of time spent on the pentobarbital $(\mathrm{Pb})$ and saline $(\mathrm{S})$ keys, and the percentage allocated to the pentobarbital key $(\% \mathrm{~Pb})$. These data are from the last five pentobarbital training sessions and the last five saline training sessions prior to the initiation of the testing phase. The group means are also shown.

\begin{tabular}{|c|c|c|c|c|c|c|c|c|c|}
\hline \multirow[b]{2}{*}{ Pigeon } & \multicolumn{3}{|c|}{ Responses } & \multicolumn{3}{|c|}{ Reinforcers } & \multicolumn{3}{|c|}{ Time } \\
\hline & $\mathrm{Pb}$ & $\mathbf{S}$ & $\% \mathrm{~Pb}$ & $\mathrm{~Pb}$ & $\mathbf{S}$ & $\% \mathrm{~Pb}$ & $\mathrm{~Pb}$ & $\mathbf{S}$ & $\% \mathrm{~Pb}$ \\
\hline \multicolumn{10}{|c|}{ Pentobarbital training sessions } \\
\hline $\mathrm{P} 257$ & 1,351 & 962 & 58 & 33 & 10 & 77 & 1,254 & 977 & 56 \\
\hline P259 & 2,417 & 1,996 & 55 & 32 & 9 & 78 & 1,213 & 1,025 & 54 \\
\hline P260 & 2,415 & 829 & 74 & 35 & 7 & 83 & 1,776 & 457 & 80 \\
\hline$M$ & 2,061 & 1,262 & 62 & 33 & 9 & 79 & 1,414 & 820 & 63 \\
\hline \multicolumn{10}{|c|}{ Saline training sessions } \\
\hline $\mathrm{P} 257$ & 312 & 1,510 & 17 & 9 & 34 & 21 & 457 & 1,773 & 20 \\
\hline P259 & 750 & 3,067 & 20 & 10 & 33 & 23 & 301 & 1,936 & 14 \\
\hline P260 & 1,124 & 1,670 & 40 & 9 & 33 & 21 & 567 & 1,662 & 25 \\
\hline$M$ & 729 & 2,082 & 26 & 9 & 33 & 21 & 442 & 1,790 & 20 \\
\hline
\end{tabular}

the number of reinforcers earned, compared to saline.

After pentobarbital administration, the percentage of responding and percentage of time allocated to the pentobarbital key under the concurrent VI 60-s VI 240-s schedule should approximate $80 \%$, and after saline administration the percentage of responding on the pentobarbital key should approximate $20 \%$, corresponding to the $4: 1$ ratio of reinforcement under the concurrent schedules if perfect matching occurs (de Villiers, 1977). For Pigeons P257 and P259, Table 1 shows that, after pentobarbital administration, the percentages of responding and time allocation under the VI 60-s schedule component were less than the percentages of obtained reinforcers. Thus, these conditions produced response percentages that were less extreme than matching. After saline administration, however, the percentages of responding and time allocation under the VI 240-s schedule for P257 and P259 were much closer to the expected values. For P260, these relationships were somewhat reversed. Under pentobarbital, the percentage of responding on the pentobarbital key approximated the percentage of obtained drug reinforcers. Under saline the percentage of responses emitted on the pentobarbital key was higher than expected, even though the percentage of time allocated and the percentage of reinforcers earned on the pentobarbital key were closer to the expected values. Thus, Pigeons P257 and P259 slightly undermatched responding after pentobarbital administration, and Pigeon P260 slightly overmatched responding on the pentobarbital key after saline administration.

Figure 1 shows the dose-effect curves for percentage of responding on the pentobarbital key and the percentage of time allocated to the pentobarbital key as a function of pentobarbital dose. As the dose of pentobarbital increased, the percentage of responding on the pentobarbital key also increased for each of the pigeons. For Pigeon P257 at the dose of $10.0 \mathrm{mg} / \mathrm{kg}$ and for P259 at the dose of $13.0 \mathrm{mg} / \mathrm{kg}$, the percentages of pentobarbital key responding were slightly higher than the percentages established under the training and the control conditions. Because of the relatively high percentage of pentobarbital key responding after saline administration by P260, and because the dose of $1.0 \mathrm{mg} / \mathrm{kg}$ pentobarbital produced approximately this same percentage of pentobarbital key responding, this bird's dose-response curve was somewhat flat. In fact, for all 3 pigeons, the percentages of responding at the $1.0 \mathrm{mg} / \mathrm{kg}$ dose of pentobarbital were approximately equal to the percentages under the training and control conditions after saline administration. Thus, the percentage of responding on the pentobarbital key was a function of the dose of pentobarbital for each of the pigeons.

The percentages of time allocated to the pentobarbital key (Figure 1) were very similar to the percentages of responding emitted on 

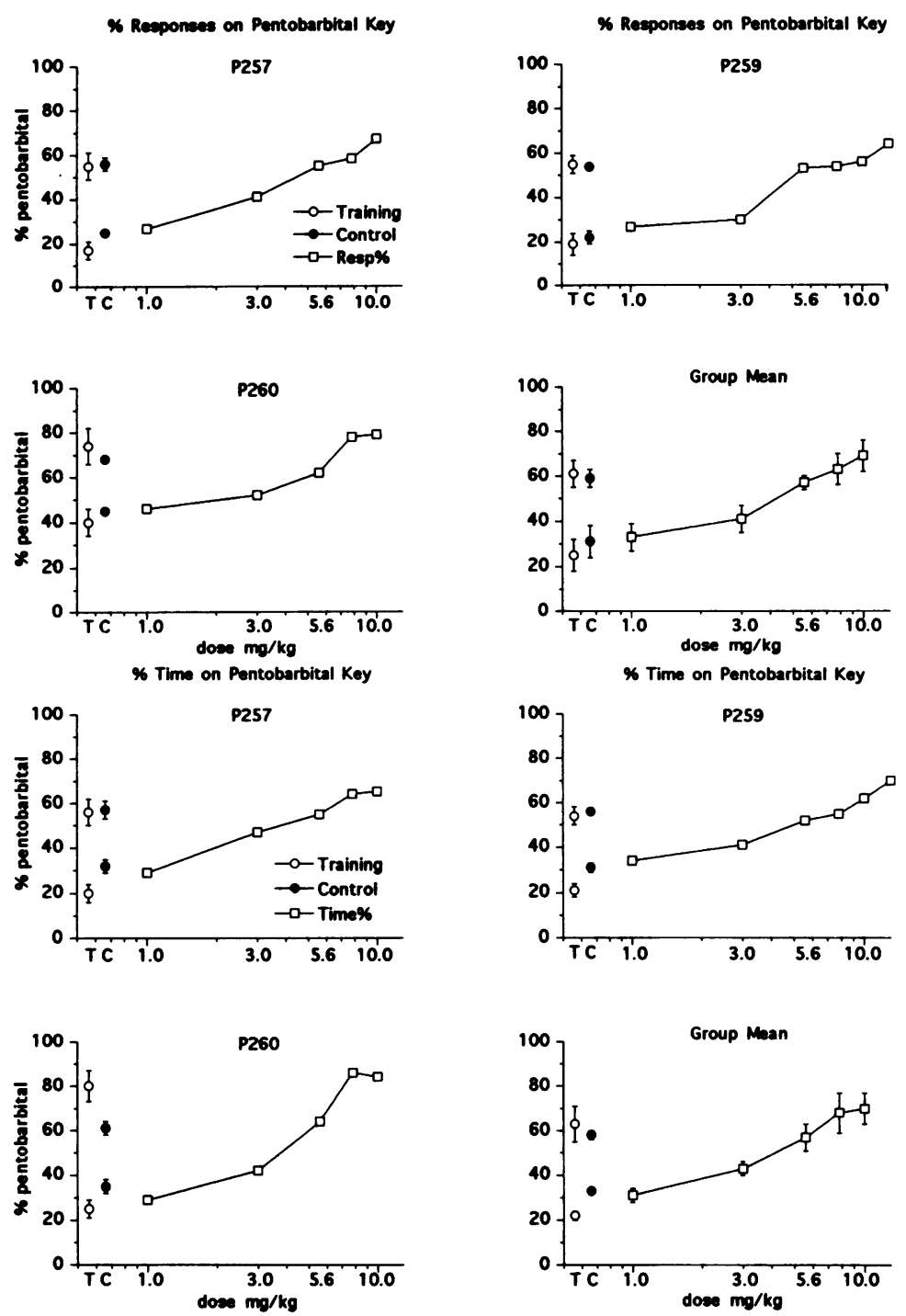

Fig. 1. The dose-response effects of pentobarbital on the percentage of pentobarbital key responding (top four graphs) and the percentage of session time allocated on the pentobarbital key (bottom four graphs) for Pigeons P257, P259, P260, and the group mean. The individual circles on the left hand side of each graph show the mean values obtained during the seven training ( $T$, open circles) and two control ( $C$, filled circles) sessions for percentage responding, or percentage time allocation, on the pentobarbital key as the pigeons responded under the pentobarbital training stimulus (upper circles) and the saline training stimulus (lower circles). The vertical lines through these circles represent \pm 1 standard deviation of the mean, as do the vertical lines through the group-mean data points. The $x$ axis on each graph extends to the dose of $13.0 \mathrm{mg} / \mathrm{kg}$ pentobarbital.

the pentobarbital key. Thus, for both P257 and P259, as the dose of pentobarbital increased above $5.6 \mathrm{mg} / \mathrm{kg}$, the percentage of time allocated to responding on the pentobarbital key increased above the percentages obtained under the control and training conditions. For all 3 pigeons, as the percentage of responses emitted on the pentobarbital key increased, the amount of time allocated to that schedule also increased. This is a typical finding for each pigeon under each drug. Because of the similarity in these data, percentage of time allocated to the pentobarbital key is not shown for the substituted drugs.

Figure 2 shows the percentage of responding on the pentobarbital key during the de- 

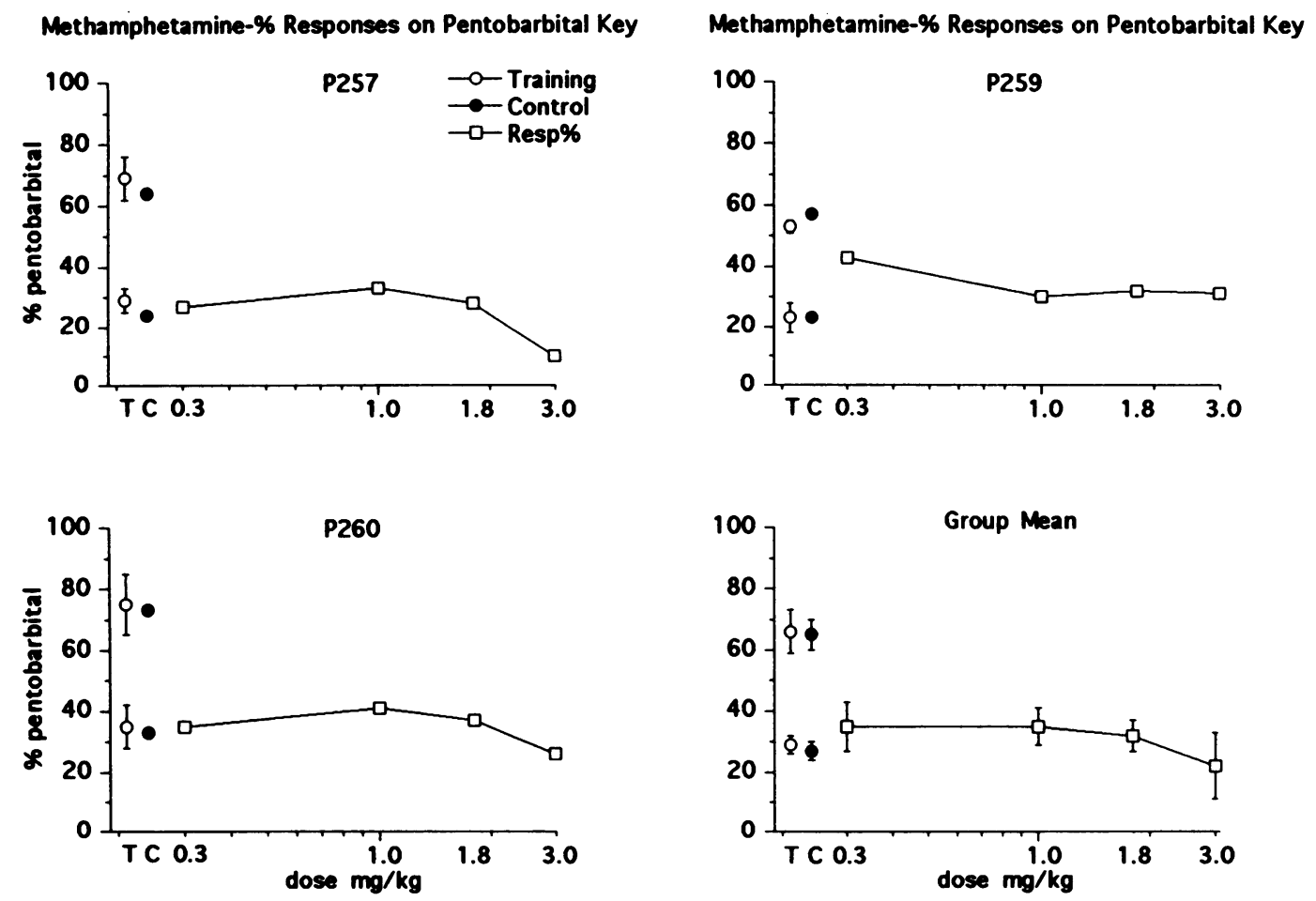

Fig. 2. The dose-response effects of methamphetamine on percentage pentobarbital responding. The individual circles on the left side of each graph show the mean values obtained during the five training ( $T$, open circles) sessions and the one control ( $\mathrm{C}$, filled circles) session for percentage responding on the pentobarbital key as the pigeons responded under the pentobarbital training stimulus (upper circles) and the saline training stimulus (lower circles). The vertical lines through these circles represent \pm 1 standard deviation of the mean, as do the vertical lines through the group-mean data points.

termination of the methamphetamine doseresponse curve. Only for P259 did the lowest dose of methamphetamine produce a clear increase in pentobarbital key responding above the saline control and training percentages. For Pigeons P257 and P260, at the high dose of methamphetamine, there was a decrease in the proportion of responding on the pentobarbital key below that established after saline administration under the training and control conditions. The methamphetamine mean substitution curve also suggests a slight decrease in percentage of pentobarbital key responding with increasing dose.

The PCP dose-response data are shown in Figure 3. Because of the disparity in the behavioral effect of PCP among the pigeons, the dose-response curves were determined twice for each bird. The results of the first and second determinations were similar. The second set of determinations is shown in Figure 3. Each of the 3 pigeons responded dif- ferently under PCP. For Pigeon P257, a dosedependent increase in the percentage of pentobarbital key responding occurred with the administration of PCP. At the dose of 1.0 $\mathrm{mg} / \mathrm{kg}$, this bird emitted $97 \%$ of its responses on the pentobarbital key. Under the concurrent VI 60-s VI 240-s training schedule, a subject would be expected to approximate a $4: 1$ ratio of responses on the pentobarbital key if the test stimulus substituted for the training dose of pentobarbital. Instead, this pigeon emitted almost 10 responses on the pentobarbital key for each response on the saline key under this dose of PCP.

As the dose of PCP increased, there was little change in the percentage of pentobarbital key responding for P259. Thus, for this bird, it does not appear as if PCP substituted for pentobarbital. Pigeon P260 failed to respond at a dose above $0.30 \mathrm{mg} / \mathrm{kg}$ PCP. Although there was a slight increase in the amount of pentobarbital key responding at 
PCP-\% Responses on Pentobarbital Key
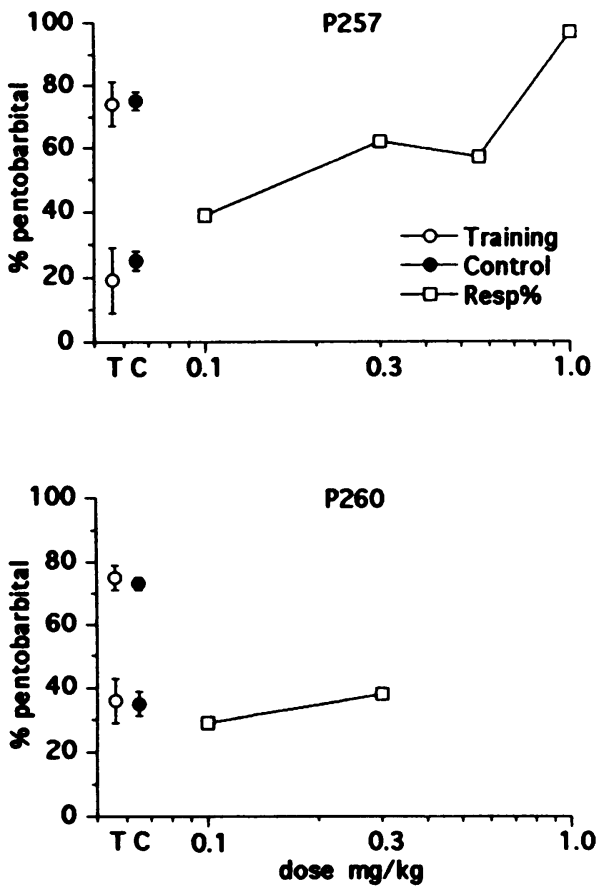

PCP-\% Responses on Pentobarbital Key
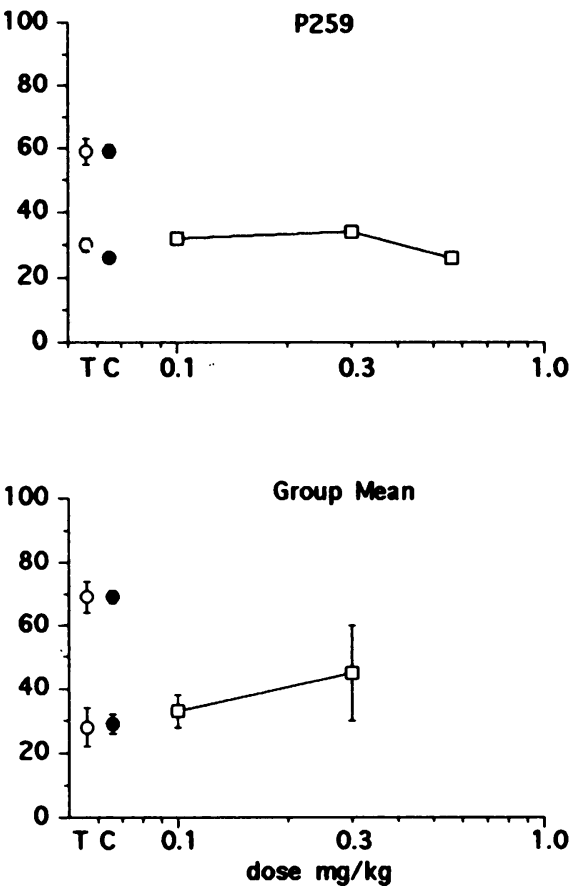

Fig. 3. The dose-response effects of PCP on percentage pentobarbital responding. The data for the training sessions are the means of seven pentobarbital stimulus sessions and seven saline stimulus sessions per pigeon. The control session data are the means of two pentobarbital and two saline stimulus sessions per pigeon. Other details are as in Figure 2.

this dose, the failure to respond at higher doses precludes any determination of the substitutability of PCP for pentobarbital for P260. Because of the differential effects of PCP, the mean data are not representative of the responding of the 3 pigeons.

The administration of chlordiazepoxide produced a dose-dependent increase in the percentage of responding on the pentobarbital key for each pigeon (Figure 4). The percentage responding by each pigeon reached, or exceeded, the baseline levels attained under the pentobarbital training and control conditions. For P259, the slope of the doseresponse curve was very shallow until the highest dose of chlordiazepoxide $(10.0 \mathrm{mg} /$ $\mathrm{kg}$ ) was reached. For each of the birds, the $1.0 \mathrm{mg} / \mathrm{kg}$ dose of chlordiazepoxide caused an increase in the percentage of pentobarbital key responding greater than that after saline administration under the training and control conditions. Individually, the peak in pentobarbital key responding occurred at the dose of $7.8 \mathrm{mg} / \mathrm{kg}$ chlordiazepoxide for $\mathrm{Pi}$ - geons P257 and P260 and at the dose of 10.0 $\mathrm{mg} / \mathrm{kg}$ for P259. The mean dose-response curve shows the relatively high percentage of pentobarbital key responding at the dose of $1.0 \mathrm{mg} / \mathrm{kg}$ chlordiazepoxide and the increase in percentage of responding on the pentobarbital key with increasing dose.

The training dose of pentobarbital (5.0 $\mathrm{mg} / \mathrm{kg}$ ) was administered in combination with differing doses of bemegride, and the percentage of responding on the pentobarbital key was used as a measure of the effects of this drug combination (Figure 5). For each pigeon, as the dose of bemegride increased, there was a corresponding decrease in the percentage of pentobarbital key responding. When bemegride was administered in combination with saline, the highest dose under which P259 and P260 continued to respond was $3.0 \mathrm{mg} / \mathrm{kg}$, whereas the highest dose for which P257 continued to respond was 10.0 $\mathrm{mg} / \mathrm{kg}$. The highest percentage of pentobarbital key responding for P257, P259, and P260 was $36 \%, 42 \%$, and $42 \%$, respectively, 
Chlordiazepoxide-\% Responses on Pentobarbital Key
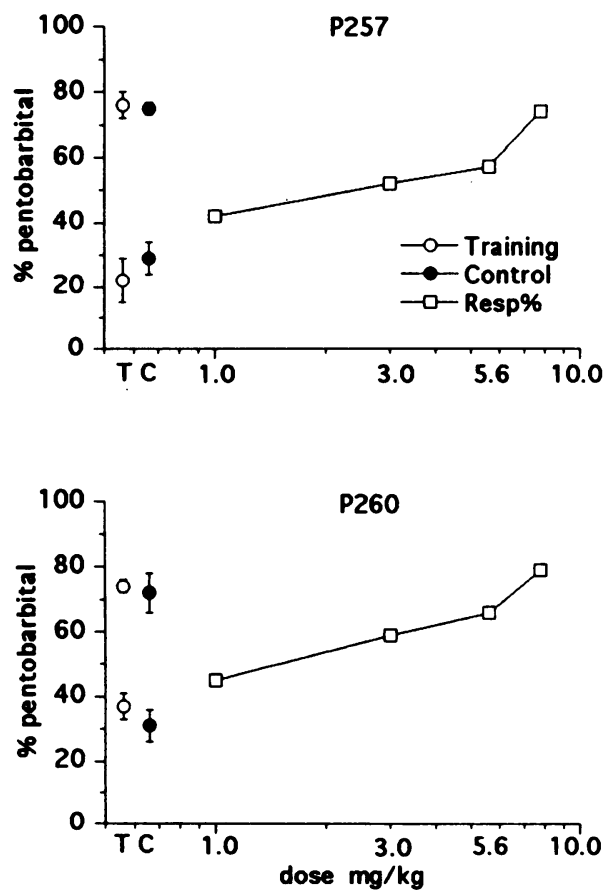

Chlordiazepoxide-\% Responses on Pentobarbital Key
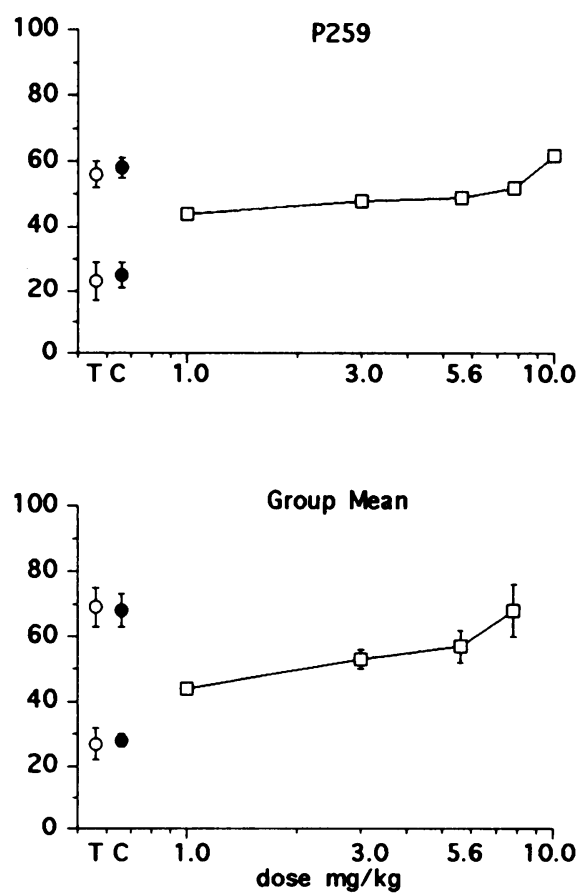

Fig. 4. The dose-response effects of chlordiazepoxide on percentage pentobarbital responding. The data for the training sessions are the means of six pentobarbital stimulus sessions and six saline stimulus sessions per pigeon. The control session data are the means of two pentobarbital and two saline stimulus sessions per pigeon. Other details are as in Figure 2.

after the administration of bemegride and saline. These percentages are slightly higher than those emitted under the saline training and control conditions. They are also equal to, or slightly lower than, the percentages emitted under the combination of the $\mathbf{5 . 0}$ $\mathrm{mg} / \mathrm{kg}$ pentobarbital dose and the $10.0 \mathrm{mg} /$ $\mathrm{kg}$ bemegride dose for P257 and P259 and the $7.8 \mathrm{mg} / \mathrm{kg}$ bemegride dose for $\mathrm{P} 260$. Thus, as Figure 5 shows, increasing the dose of bemegride produced a decrease in the control of responding by the $5.0 \mathrm{mg} / \mathrm{kg}$ dose of pentobarbital.

The results of the final substitution test are shown in Figure 6. This figure shows the data obtained during the second determination of the pentobarbital dose-response curve for percentage responding and for time allocation. For P257 and P260 there was a high degree of similarity in percentage responding on the pentobarbital key under the first (Figure 1) and second pentobarbital dose-response curves. Pigeon P259, unlike during the first pentobarbital dose-response deter- mination, decreased its percentage of responding on the pentobarbital key at doses greater than $5.6 \mathrm{mg} / \mathrm{kg}$ during the second pentobarbital determination. The mean dose-response curve for percentage of pentobarbital key responding under the second determination, however, was similar to the mean curve of the first pentobarbital doseresponse determination.

The results of the second pentobarbital dose-response determination showed that the percentage of total session time allocated to the pentobarbital key was an increasing function of drug dose (Figure 6). Thus, the pigeons allocated their time between the concurrent schedules essentially the same as they did during the first pentobarbital dose-response determination. These data also show that the decrease in the percentage of pentobarbital key responding by P259 under the second determination was not caused by a decrease in the amount of time allocated to responding on the pentobarbital key. 
Bemegride-\% Responses on Pentobarbital Key
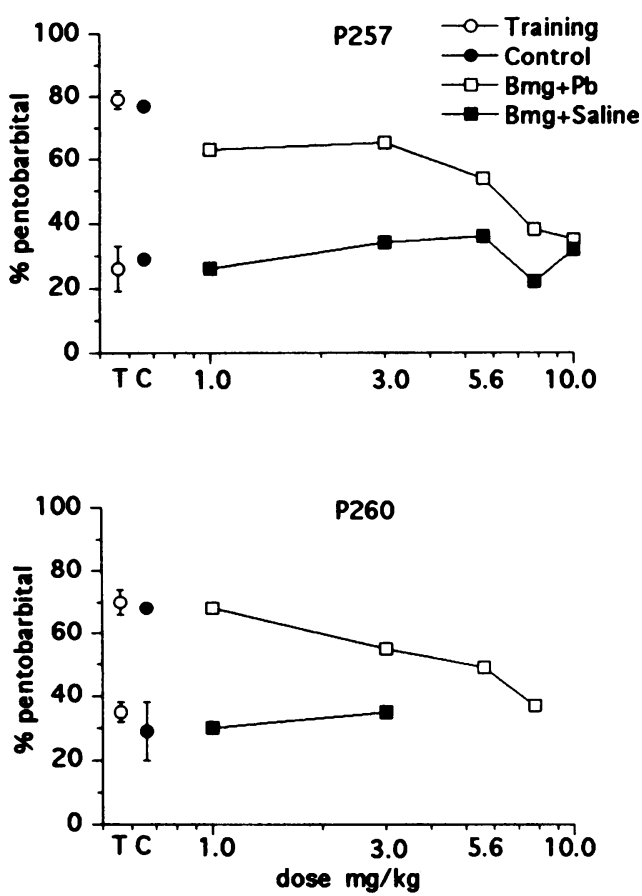

Bemegride-\% Responses on Pentobarbital Key
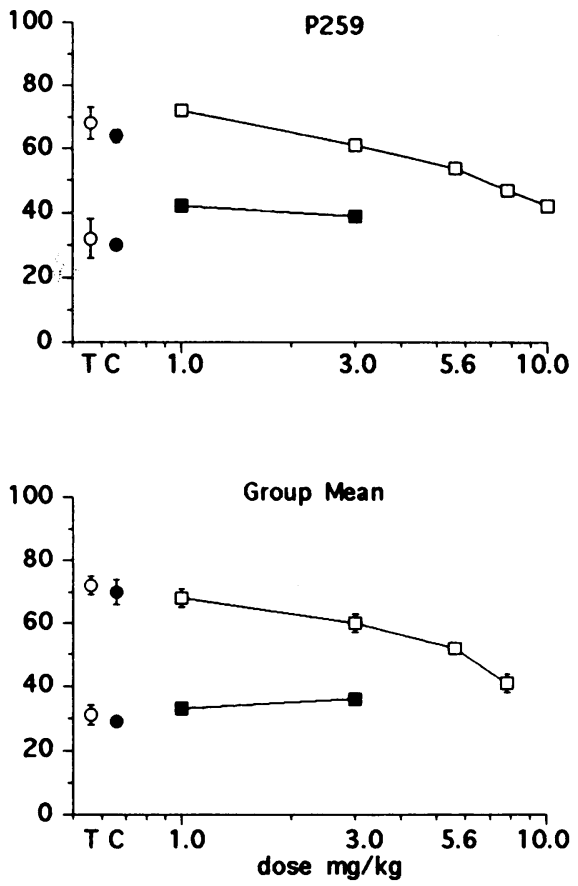

Fig. 5. The dose-response effects of bemegride in combination with the training dose of pentobarbital (open squares) and the saline training stimulus (filled squares) on percentage pentobarbital responding. The data for the training sessions are the means of six pentobarbital stimulus sessions and six saline stimulus sessions per pigeon. The control session data are the means of two pentobarbital and two saline stimulus sessions per pigeon. Other details are as in Figure 2.

\section{DISCUSSION}

In the present study, a pentobarbital discrimination was established and maintained under the behavioral contingencies of a concurrent VI 60-s VI 240-s schedule of reinforcement. Thus, pigeons can discriminate between the presence and the absence of a drug stimulus while responding under relative reinforcement contingencies. The results of this study also showed that the administration of the novel test drugs produced a pattern of substitution for pentobarbital that was very similar to the pattern seen in earlier studies (Barry \& Krimmer, 1978; Herling et al., 1980; Snodgrass \& McMillan, 1991). Therefore, establishing the pentobarbital discrimination under the relative reinforcement contingencies of the concurrent schedule did not alter the qualitative manner in which the drugs substituted for the pentobarbital stimulus. On a quantitative basis, however, establishing the pentobarbital discrimination under the concurrent VI VI schedule resulted in indi- vidual dose-response curves that, instead of being quantal, were graded in form.

During the pentobarbital and saline training and control sessions, the relationship between pentobarbital key and saline key responding should have approximated an $80 \% / 20 \%$ distribution of responding if perfect matching had occurred. In studies of the matching law using concurrent VI VI schedules, however, the usual result is not perfect matching, but undermatching of response proportions (Baum, 1979). Thus, although the training and control data of the present study resulted in response percentages less than would occur with perfect matching, this result is consistent with data from other investigations of the matching process (cf. Williams, 1988).

Because, in the present study, the pigeons responded under the concurrent VI 150-s VI 150 -s schedule during the test sessions, it was necessary to conduct control sessions to determine if these reinforcement contingencies 

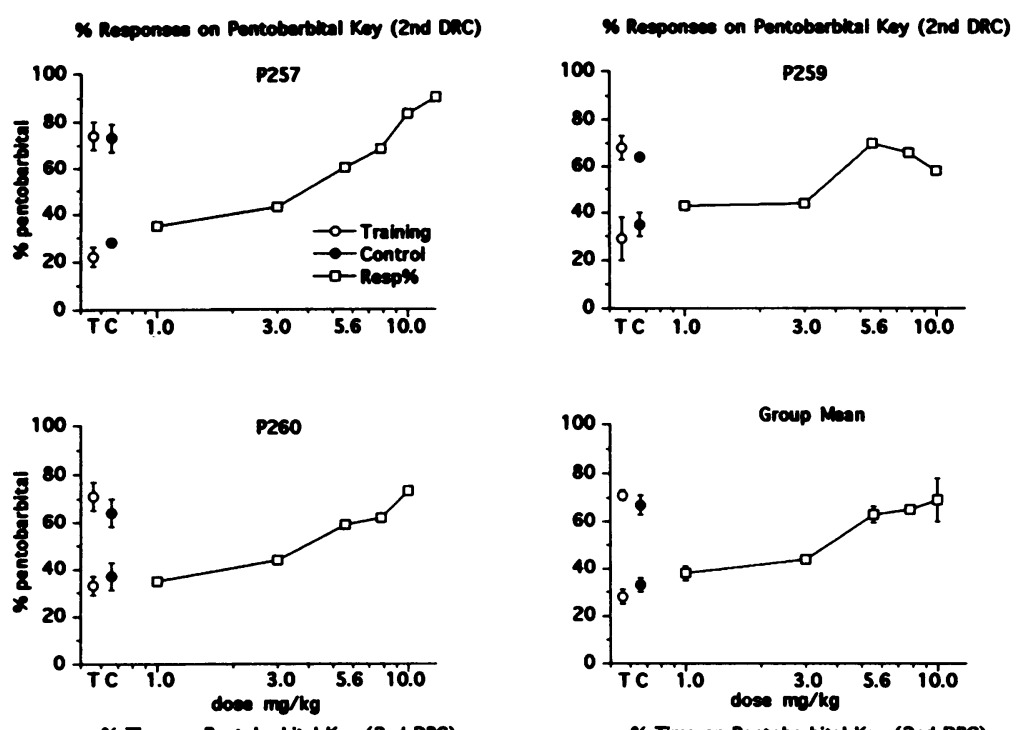

* Time on Pentobartital Key (2nd DRC)
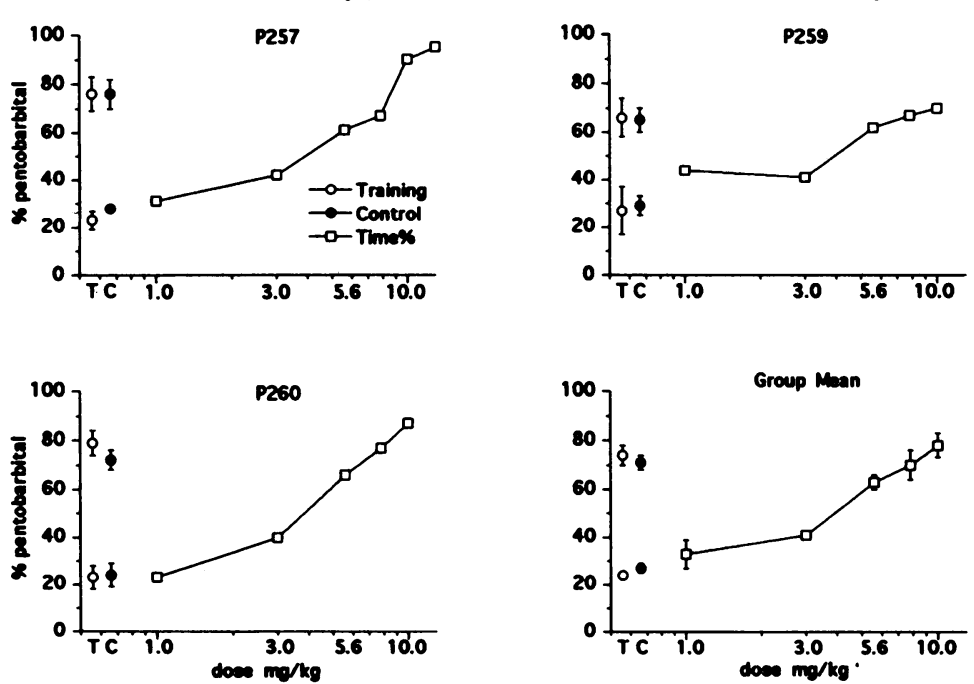

Fig. 6. The second pentobarbital dose-response curve (DRC) determination. The data for the training sessions are the means of seven pentobarbital stimulus sessions and seven saline stimulus sessions per pigeon. The control session data are the means of three pentobarbital and three saline stimulus sessions per pigeon. Details are as in Figure 1 .

would disrupt stimulus control. During the control sessions, saline and the training dose of pentobarbital were administered as the pigeons responded under the concurrent VI 150-s VI 150-s schedule of reinforcement. Thus, if the training stimuli failed to control responding, during these control sessions the response percentages should have approximated $50 \%$ on each key. The results of these control sessions showed, however, that the relative responding remained appropriate for the concurrent VI 60-s VI 240-s training schedule. Thus, the association between the saline and pentobarbital discriminative stimuli and the differential reinforcement contingencies established during training continued to control responding under the concurrent VI 150-s VI 150-s schedule.

Under the concurrent schedule, responses on both keys are reinforced in the presence of each of the training stimuli. Therefore, the discrimination is not based on which re- 
sponse produced the reinforcer but, rather, on the rate of reinforcement on the pentobarbital key relative to the rate of reinforcement on the saline key. The matching of relative rates of responding and relative rates of reinforcement is a molar process (i.e., it is time dependent; Davison \& McCarthy, 1988; Herrnstein \& Loveland, 1975). Because matching will occur only when adequate time is allowed for behavior to adjust to the reinforcement contingencies, it was necessary to use the overall session data to determine the pigeons' relative response rate in the present study.

Under the reinforcement and extinction conditions of the typical FR schedule drug discrimination procedure, the control conditions set the upper and lower limits of responding. One of the advantages of the concurrent VI VI schedule drug discrimination procedure is that ceiling and floor effects are not produced by the control procedure. Therefore, with this concurrent schedule procedure, if a drug stimulus dose-dependently substitutes for the pentobarbital stimulus, then it is possible that the percentage of responding on, as well as the percentage of time allocated to, the pentobarbital key may be greater than that produced under the pentobarbital control conditions. This effect occurred under the first pentobarbital dose-response determination in the present study. While responding under the higher doses of pentobarbital, each of the pigeons emitted a greater percentage of responses, and spent a greater percentage of session time, on the pentobarbital key than they did under the pentobarbital control conditions (Figure 1). This effect can also be seen for Pigeons P257 and P260 under the second pentobarbital dose-response determination (Figure 6) and for the responding of Pigeon P257 at the dose of $1.0 \mathrm{mg} / \mathrm{kg}$ PCP (Figure 3).

Under drug discrimination procedures that use all-or-none reinforcement contingencies, the percentages of responding on the drug key are typically close to $100 \%$ for the training drug condition and approximately zero under the vehicle condition. Therefore, during dose-response determinations, as the response percentages approach these extreme values, data compression will occur (Stolerman, 1991). With the present procedure, however, the percentage responding under the training conditions is controlled by the relative reinforcement rate. By programming moderate levels of relative reinforcement, it should be possible to establish moderate levels of responding under both stimulus conditions. Thus, if these moderate levels are emitted under the control conditions, as in the present study, then the subject might be able to respond without data compression distorting the high and low values. Data compression caused by extremely high and extremely low control values is one of the factors that limits the measurement of drug discrimination data to the ordinal scale (Stolerman, 1991). If subjects were able to produce data without arbitrary constraints at the extreme values, it is more likely that measurement of the data could be obtained on an interval scale. If so, it would be possible to analyze drug discrimination data with procedures that legitimately use the mean and standard deviation as measures of central tendency (Stevens, 1951). Other approaches that might be useful to pursue include behavioral approaches to signal detection (e.g., Alsop \& Davison, 1991).

There was no indication that methamphetamine substituted for pentobarbital. In fact, as the dose of methamphetamine increased, the percentage responding of P257, and possibly $\mathrm{P} 260$, on the pentobarbital key actually decreased. Because the percentage responding on the pentobarbital key after saline administration was approximately $30 \%$ instead of zero, it was possible for the birds to show a decrease in the percentage of responding on the pentobarbital key below that produced by saline administration. Thus, it may be that methamphetamine was a more salient cue for signaling a decrease in reinforcement rate on the pentobarbital key than occurred after saline administration for one or both of these pigeons.

PCP administration produced different effects on the responding of each pigeon. Although the reason for these differences is unclear, the results are not unusual. PCP has been reported to produce different degrees of drug substitution among subjects trained to discriminate pentobarbital from its absence (Snodgrass \& McMillan, 1991; Willetts \& Balster, 1989). Thus, the fact that Pigeon P257 responded as if PCP was pentobarbital and P259 responded as if PCP and pentobar- 
bital were qualitatively distinct should not be too surprising. However, for P257, the percentage of pentobarbital key responding produced by the $1.0 \mathrm{mg} / \mathrm{kg}$ dose of PCP was unusual. At this dose, P257 emitted 97\% of its total responses on the pentobarbital key. In contrast, for P259, PCP administration produced a relatively flat dose-response curve, indicative of a lack of substitution of PCP for pentobarbital. P260 failed to respond at doses of PCP above $0.3 \mathrm{mg} / \mathrm{kg}$. Thus, there is insufficient data to determine the relationship of PCP to that of pentobarbital for P260.

Chlordiazepoxide has been reported to substitute for pentobarbital in rats (Barry \& Krimmer, 1978). In the present study, the administration of chlordiazepoxide produced a dose-dependent increase in percentage of pentobarbital key responding by each pigeon. In fact, at the highest dose of chlordiazepoxide that did not eliminate responding, all 3 of the birds approximately equaled the percentage responding that they emitted under the pentobarbital control condition.

The administration of bemegride, when combined with the training dose of pentobarbital, has been reported to dose-dependently block the pentobarbital stimulus in pigeons (Herling \& Winger, 1981). The present results are consistent with this finding, in that bemegride produced a dose-dependent decrease in the percentage of responding on the pentobarbital key by each of the pigeons when it was administered in combination with the $5.0 \mathrm{mg} / \mathrm{kg}$ dose of pentobarbital. The present results also show that the percentage decrease in pentobarbital key responding by the individual pigeons was a graded function of the combined pentobarbital and bemegride dose.

In the present study the dose-response curves of individual pigeons were graded in form. Holloway and Gauvin (1989), Stolerman (1991), and Young (1991) all have emphasized the importance of the schedule of reinforcement in determining whether the drug discrimination dose-response curve is quantal or graded. Stimuli, in the form of drug doses, clearly can be varied quantitatively. Whether an organism's behavior is controlled by graded variations in stimulus intensity (drug dose) or in an all-or-nothing manner may depend largely on the schedule of reinforcement that is maintaining the be- havior. Both Colpaert (1985) and Stolerman (1991) have emphasized the importance of determining whether the dependent variable (stimulus control) in drug discrimination studies is graded or quantal. This is an important question about the fundamental nature of stimulus control by drugs, because graded dose-response curves suggest that there is a continuum of stimulus control produced by the different doses of drugs. Points in the middle of the dose-effect curve, where responding occurs on both keys, would reflect the dose-dependent degree of stimulus control, and if equal distances along the measurement scale represent equal differences in the magnitude of stimulus control, then measurement of stimulus control will be on an interval scale (cf. Gescheider, 1985; Stevens, 1951).

Conversely, if stimulus control by drug stimuli is quantal, it would suggest that stimulus control is provided by the presence or absence of the drug stimulus. Intermediate points on quantal dose-response curves that are not artifacts of averaging might reflect the probability of the organism detecting the presence of the drug stimulus at doses differing in magnitude from the training dose. It may be, however, that neither graded nor quantal responding is fundamental in drug discrimination experiments, and that whether a graded or a quantal dose-response curve occurs is a function of the schedule of reinforcement that is maintaining the responding.

\section{REFERENCES}

Alsop, B., \& Davison, M. C. (1991). Effects of varying stimulus disparity and the reinforcer ratio in concurrent-schedule and signal-detection procedures. Journal of the Experimental Analysis of Behavior, 56, 67-80.

Barry, H., III, \& Krimmer, E. C. (1978). Similarities and differences in discriminative stimulus effects of chlordiazepoxide, pentobarbital, ethanol, and other sedatives. In F. C. Colpaert \& J. A. Rosecrans (Eds.), Stimulus properties of drugs: Ten years of progress (pp. 31-51). Amsterdam: Elsevier.

Baum, W. M. (1979). Matching, undermatching, and overmatching in studies of choice. Journal of the Experimental Analysis of Behavior, 32, 269-281.

Branch, M. N. (1991). Behavioral pharmacology. In I. H. Iversen \& K. A. Lattal (Eds.), Techniques in the behavioral and neural sciences: Vol. 6. Experimental analysis of behavior, Part 2 (pp. 21-77). Amsterdam: Elsevier.

Catania, A. C. (1966). Concurrent operants. In W. K. Honig (Ed.), Operant behavior: Areas of research and ap- 
plication (pp. 213-270). New York: Appleton-CenturyCrofts.

Catania, A. C., \& Reynolds, G. S. (1968). A quantitative analysis of the responding maintained by interval schedules of reinforcement. Journal of the Experimental Analysis of Behavior, 11, 327-383.

Colpaert, F. C. (1985). Drug discrimination and the behavioural analysis of drug action. In C. F. Lowe, M. Richelle, D. E. Blackman, \& C. M. Bradshaw (Eds.), Behaviour analysis and contemporary psychology (pp. 205216). London: Erlbaum.

Colpaert, F. C. (1986). Drug discrimination: Behavioral, pharmacological, and molecular mechanisms of discriminative drug effects. In S. R. Goldberg \& I. P. Stolerman (Eds.), Behavioral analysis of drug dependence (pp. 161-193). Orlando, FL: Academic Press.

Colpaert, F. C. (1987). Drug discrimination: Methods of manipulation, measurement, and analysis. In $\mathbf{M}$. A. Bozarth (Ed.), Methods of assessing the reinforcing property of abused drugs (pp. 341-372). New York: SpringerVerlag.

Colpaert, F. C. (1991). The discriminative response: An elementary particle of behavior. Behavioural Pharmacology, 2, 283-286.

Davison, M., \& McCarthy, D. (1980). Reinforcement for errors in a signal-detection procedure. Journal of the Experimental Analysis of Behavior, 34, 35-47.

Davison, M., \& McCarthy, D. (1988). The matching law: A research review. Hillsdale, NJ: Erlbaum.

de Villiers, P. A. (1977). Choice in concurrent schedules and a quantitative formulation of the law of effect. In W. K. Honig \& J. E. R. Staddon (Eds.), Handbook of operant behavior (pp. 233-287). Englewood Cliffs, NJ: Prentice Hall.

Fleshler, M., \& Hoffman, H. S. (1962). A progression for generating variable-interval schedules. Journal of the Experimental Analysis of Behavior, 5, 529-530.

Gescheider, G. A. (1985). Psychophysics: Method, theory, and application (2nd ed.). Hillsdale, NJ: Erlbaum.

Herling, S., Valentino, R. J., \& Winger, G. D. (1980). Discriminative stimulus effects of pentobarbital in pigeons. Psychopharmacology, 71, 21-28.

Herling, S., \& Winger, G. (1981). Selective blockade of the discriminative effects of pentobarbital in pigeons. Psychopharmacology, 75, 321-323.

Herrnstein, R. J., \& Loveland, D. H. (1975). Maximizing and matching on concurrent ratio schedules. Journal of the Experimental Analysis of Behavior, 24, 107-116.

Holloway, F. A., \& Gauvin, D. V. (1989). Comments on method and theory in drug discrimination: A potpourri of problems, perplexities, and possibilities. Drug Development Research, 16, 195-207.

Koek, W., \& Slangen, J. L. (1982). Effects of reinforcement differences between drug and saline sessions on discriminative stimulus properties of fentanyl. In F. C. Colpaert \& J. L. Slangen (Eds.), Drug discrimination: Applications in CNS pharmacology (pp. 343-354). Amsterdam: Elsevier.

Logue, A. W. (1983). Signal detection and matching: Analyzing choice on concurrent variable-interval schedules. Journal of the Experimental Analysis of Behav ior, 39, 107-127.

Massey, B. W., McMillan, D. E., \& Wessinger, W. D. (1992). Discriminative-stimulus control by morphine in the pigeon under a fixed-interval schedule of reinforcement. Behavioral Pharmacology, 3, 475-488.

McMillan, D. E., \& Wenger, G. R. (1984). Bias of phencyclidine discrimination by the schedule of reinforcement. Journal of the Experimental Analysis of Behavior, 42, 51-66.

Nevin, J. A., Jenkins, P., Whittaker, S., \& Yarensky, P. (1982). Reinforcement contingencies and signal detection. Journal of the Experimental Analysis of Behavior, $37,65-79$.

Overton, D. A. (1979). Influence of shaping procedures and schedules of reinforcement on performance in the two-bar drug discrimination task: A methodological report. Psychopharmacology, 65, 291-298.

Overton, D. A. (1984). State dependent learning and drug discrimination. In L. L. Iverson, S. D. Iverson, \& S. H. Snyder (Eds.), Handbook of psychopharmacology (Vol. 18, pp. 59-128). New York: Plenum.

Overton, D. A. (1988). Similarities and differences between behavioral control by drug-produced stimuli and by sensory stimuli. In F. C. Colpaert \& $R$. L. Balster (Eds.), Transduction mechanisms of drug stimuli: Psy chopharmacology series 4 (pp. 177-198). Berlin: Springer-Verlag.

Snodgrass, S. H., \& McMillan, D. E. (1991). Effects of schedule of reinforcement on a pentobarbital discrimination in rats. Journal of the Experimental Analysis of Behavior, 56, 313-329.

Stevens, S. S. (1951). Mathematics, measurement, and psychophysics. In S. S. Stevens (Ed.), Handbook of experimental psychology (pp. 1-49). New York: Wiley.

Stolerman, I. P. (1989). Discriminative stimulus effects of nicotine in rats trained under different schedules of reinforcement. Psychopharmacology, 97, 131-138.

Stolerman, I. P. (1991). Measures of stimulus generalization in drug discrimination experiments. Behavioural Pharmacology, 2, 265-282.

Willetts, J., \& Balster, R. L. (1989). Pentobarbital-like stimulus effects of N-methyl-D-aspartate antagonists. Journal of Pharmacology and Experimental Therapeutics, 249, 438-443.

Williams, B. A. (1988). Reinforcement, choice, and response strength. In R. C. Atkinson, R. J. Herrnstein, G. Lindzey, \& R. D. Luce (Eds.), Stevens' handbook of experimental psychology: Vol. 2, Learning and cognition (pp. 167-244). New York: Wiley.

Young, A. M. (1991). The time is ripe for an experimental analysis of measurement issues. Behavioural Pharmacology, 2, 287-291.

Young, A. M., \& Sannerud, C. A. (1991). Tolerance to drug discriminative stimuli. In A. J. Goudie \& $\mathrm{M}$. W. Emmett-Oglesby (Eds.), Psychoactive drugs: Tolerance and sensitization (pp. 221-280). Clifton, NJ: Humana Press.

Received October 24, 1994 Final acceptance January 22, 1996 


\section{APPENDIX}

For each pigeon, the data for the pentobarbital (Pen) and saline (Sal) control sessions and the dose-response data for each drug are shown. These data are the number of changeover delays (COD), the number of responses, reinforcers, and amount of time allocated to the pentobarbital $(\mathrm{Pb})$ and saline $(\mathrm{S})$ keys, and the percentage of responses and time emitted on the pentobarbital key $(\% \mathrm{~Pb})$.

\begin{tabular}{|c|c|c|c|c|c|c|c|c|c|c|}
\hline \multirow[b]{2}{*}{ Pigeon } & \multirow[b]{2}{*}{$\mathrm{mg} / \mathrm{kg}$} & \multirow[b]{2}{*}{ COD } & \multicolumn{3}{|c|}{ Responses } & \multicolumn{2}{|c|}{ Reinforcers } & \multicolumn{3}{|c|}{ Time } \\
\hline & & & $\mathrm{Pb}$ & $\mathbf{S}$ & $\% \mathrm{~Pb}$ & $\mathrm{~Pb}$ & $\mathbf{S}$ & $\mathrm{Pb}$ & $\mathbf{S}$ & $\% \mathrm{~Pb}$ \\
\hline \multicolumn{11}{|c|}{ Pentobarbital } \\
\hline \multirow[t]{7}{*}{ P257 } & Pen & 218 & 1,223 & 977 & 56 & 15 & 13 & 1,317 & 977 & 57 \\
\hline & Sal & 156 & 433 & 1,317 & 25 & 12 & 15 & 729 & 1,564 & 32 \\
\hline & 1.0 & 147 & 484 & 1,326 & 27 & 12 & 12 & 662 & 1,643 & 29 \\
\hline & 3.0 & 282 & 961 & 1,369 & 41 & 12 & 11 & 1,076 & 1,233 & 47 \\
\hline & 5.6 & 170 & 1,572 & 1,278 & 55 & 13 & 14 & 1,251 & 1,042 & 55 \\
\hline & 7.8 & 148 & 1,425 & 1,031 & 58 & 14 & 9 & 1,483 & 826 & 64 \\
\hline & 10.0 & 212 & 1,864 & 934 & 67 & 13 & 13 & 1,494 & 803 & 65 \\
\hline \multirow[t]{8}{*}{ P259 } & Pen & 254 & 2,494 & 2,160 & 54 & 16 & 14 & 1,269 & 1,016 & 56 \\
\hline & Sal & 141 & 814 & 2,853 & 22 & 12 & 16 & 714 & 1,576 & 31 \\
\hline & 1.0 & 129 & 907 & 2,403 & 27 & 11 & 16 & 780 & 1,513 & 34 \\
\hline & 3.0 & 176 & 1,434 & 3,426 & 30 & 13 & 18 & 923 & 1.354 & 41 \\
\hline & 5.6 & 262 & 2,628 & 2,328 & 53 & 15 & 13 & 1,182 & 1,107 & 52 \\
\hline & 7.8 & 205 & 2,483 & 2,087 & 54 & 15 & 13 & 1,264 & 1,025 & 55 \\
\hline & 10.0 & 230 & 2,535 & 2,029 & 56 & 15 & 10 & 1,430 & 871 & 62 \\
\hline & 13.0 & 200 & 2,878 & 1,624 & 64 & 11 & 15 & 1,601 & 696 & 70 \\
\hline \multirow[t]{7}{*}{ P260 } & Pen & 167 & 2,364 & 1,132 & 68 & 15 & 14 & 1,397 & 890 & 61 \\
\hline & Sal & 188 & 1,728 & 2,141 & 45 & 14 & 15 & 804 & 1,484 & 35 \\
\hline & 1.0 & 231 & 1,717 & 2,027 & 46 & 15 & 16 & 650 & 1,627 & 29 \\
\hline & 3.0 & 233 & 2,091 & 1,929 & 52 & 16 & 15 & 956 & 1,321 & 42 \\
\hline & 5.6 & 209 & 2,491 & 1,532 & 62 & 12 & 15 & 1,460 & 833 & 64 \\
\hline & 7.8 & 105 & 2,272 & 642 & 78 & 15 & 15 & 1,958 & 323 & 86 \\
\hline & 10.0 & 78 & 2,201 & 583 & 79 & 14 & 9 & 1,931 & 378 & 84 \\
\hline \multicolumn{11}{|c|}{ Methamphetamine } \\
\hline \multirow[t]{6}{*}{ P257 } & Pen & 196 & 1,472 & 820 & 64 & 14 & 11 & 1,618 & 681 & 70 \\
\hline & Sal & 123 & 316 & 979 & 24 & 11 & 14 & 705 & 1,596 & 31 \\
\hline & 0.3 & 121 & 382 & 1,040 & 27 & 13 & 15 & 711 & 1,578 & 31 \\
\hline & 1.0 & 162 & 481 & 977 & 33 & 15 & 13 & 720 & 1,569 & 31 \\
\hline & 1.8 & 112 & 465 & 1,219 & 28 & 15 & 10 & 602 & 1,699 & 26 \\
\hline & 3.0 & 97 & 117 & 999 & 10 & 10 & 13 & 614 & 1,695 & 27 \\
\hline \multirow[t]{6}{*}{ P259 } & Pen & 216 & 2,837 & 2,145 & 57 & 14 & 16 & 1,259 & 1,022 & 55 \\
\hline & Sal & 122 & 702 & 2,322 & 23 & 14 & 15 & 507 & 1,778 & 22 \\
\hline & 0.3 & 202 & 1,316 & 1,724 & 43 & 13 & 13 & 669 & 1,628 & 29 \\
\hline & 1.0 & 175 & 1,071 & 2,496 & 30 & 12 & 12 & 607 & 1,698 & 26 \\
\hline & 1.8 & 200 & 1,063 & 2,266 & 32 & 16 & 12 & 709 & 1,580 & 31 \\
\hline & 3.0 & 229 & 1,299 & 2,926 & 31 & 15 & 15 & 694 & 1,587 & 30 \\
\hline \multirow[t]{6}{*}{ P260 } & Pen & 145 & 2,529 & 930 & 73 & 15 & 14 & 1,814 & 471 & 79 \\
\hline & Sal & 172 & 902 & 1,833 & 33 & 13 & 14 & 752 & 1,541 & 33 \\
\hline & 0.3 & 217 & 1,125 & 2,072 & 35 & 15 & 17 & 998 & 1,275 & 44 \\
\hline & 1.0 & 208 & 1,202 & 1,698 & 41 & 16 & 15 & 1,060 & 1,217 & 47 \\
\hline & 1.8 & 183 & 1,213 & 2,033 & 37 & 14 & 12 & 912 & 1,385 & 40 \\
\hline & 3.0 & 108 & 612 & 1,753 & 26 & 10 & 14 & 672 & 1,633 & 29 \\
\hline \multicolumn{11}{|l|}{ PCP } \\
\hline \multirow[t]{6}{*}{ P257 } & Pen & 80 & 1,387 & 453 & 75 & 14 & 12 & 1,798 & 502 & 78 \\
\hline & Sal & 103 & 349 & 1,073 & 25 & 12 & 14 & 657 & 1,642 & 29 \\
\hline & 0.1 & 170 & 675 & 1,057 & 39 & 15 & 16 & 1,001 & 1,276 & 44 \\
\hline & 0.3 & 110 & 1,083 & 676 & 62 & 12 & 13 & 1,579 & 722 & 69 \\
\hline & 0.56 & 79 & 769 & 581 & 57 & 13 & 13 & 1,421 & 876 & 62 \\
\hline & 1.0 & 16 & 1,403 & 48 & 97 & 15 & 1 & 2,180 & 157 & 93 \\
\hline P259 & Pen & 249 & 2,197 & 1,539 & 59 & 15 & 16 & 1,433 & 846 & 63 \\
\hline & Sal & 190 & 947 & 2,703 & 26 & 14 & 16 & 556 & 1,725 & 24 \\
\hline & 0.1 & 206 & 1,052 & 2,205 & 32 & 14 & 15 & 797 & 1,488 & 35 \\
\hline & 0.3 & 235 & 1,307 & 2,564 & 34 & 12 & 15 & 810 & 1,483 & 35 \\
\hline & 0.56 & 93 & 570 & 1,646 & 26 & 12 & 11 & 995 & 1,314 & 43 \\
\hline
\end{tabular}




\section{APPENDIX}

(Continued)

\begin{tabular}{|c|c|c|c|c|c|c|c|c|c|c|}
\hline \multirow[b]{2}{*}{ Pigeon } & \multirow[b]{2}{*}{ mg/kg } & \multirow[b]{2}{*}{ COD } & \multicolumn{3}{|c|}{ Responses } & \multicolumn{2}{|c|}{ Reinforcers } & \multicolumn{3}{|c|}{ Time } \\
\hline & & & $\mathrm{Pb}$ & $\mathbf{S}$ & $\% \mathbf{P b}$ & $\mathbf{P b}$ & $\mathbf{S}$ & $\mathbf{P b}$ & $\mathbf{S}$ & $\% \mathrm{~Pb}$ \\
\hline \multicolumn{11}{|c|}{ PCP, continued } \\
\hline \multirow[t]{4}{*}{ P260 } & Pen & 134 & 2,191 & 824 & 73 & 16 & 13 & 1,784 & 502 & 78 \\
\hline & Sal & 172 & 1,021 & 1,841 & 35 & 12 & 15 & 736 & 1,562 & 32 \\
\hline & 0.1 & 174 & 819 & 2,012 & 29 & 11 & 12 & 645 & 1,664 & 28 \\
\hline & 0.3 & 217 & 1,005 & 1,643 & 38 & 14 & 12 & 937 & 1,360 & 41 \\
\hline \multicolumn{11}{|c|}{ Chlordiazepoxide } \\
\hline \multirow[t]{6}{*}{ P257 } & Pen & 129 & 1,622 & 537 & 75 & 16 & 13 & 1,780 & 445 & 80 \\
\hline & Sal & 145 & 434 & 1,069 & 29 & 11 & 15 & 607 & 1,695 & 26 \\
\hline & 1.0 & 136 & 695 & 972 & 42 & 14 & 12 & 975 & 1,322 & 42 \\
\hline & 3.0 & 146 & 929 & 862 & 52 & 13 & 16 & 1,337 & 948 & 61 \\
\hline & 5.6 & 68 & 588 & 447 & 57 & 15 & 11 & 1,648 & 649 & 72 \\
\hline & 7.8 & 81 & 850 & 299 & 74 & 16 & 15 & 1,710 & 567 & 75 \\
\hline \multirow[t]{7}{*}{ P259 } & Pen & 307 & 2,610 & 1,851 & 58 & 14 & 14 & 1,386 & 905 & 60 \\
\hline & Sal & 178 & 957 & 2,897 & 25 & 12 & 17 & 570 & 1,720 & 25 \\
\hline & 1.0 & 267 & 2,084 & 2,697 & 44 & 14 & 18 & 829 & 1,444 & 36 \\
\hline & 3.0 & 302 & 1,849 & 2,004 & 48 & 16 & 12 & 1,168 & 1,121 & 51 \\
\hline & 5.6 & 233 & 2,089 & 2,187 & 49 & 17 & 18 & 1,018 & 1,243 & 45 \\
\hline & 7.8 & 199 & 2,092 & 1,952 & 52 & 15 & 18 & 1,271 & 998 & 56 \\
\hline & 10.0 & 190 & 2,472 & 1,529 & 62 & 15 & 16 & 1,229 & 1,048 & 54 \\
\hline \multirow[t]{6}{*}{ P260 } & Pen & 137 & 2,092 & 822 & 72 & 14 & 15 & 1,657 & 631 & 72 \\
\hline & Sal & 119 & 734 & 1,632 & 31 & 12 & 15 & 694 & 1,652 & 29 \\
\hline & 1.0 & 195 & 1,356 & 1,659 & 45 & 13 & 15 & 830 & 1,459 & 36 \\
\hline & 3.0 & 247 & 1,592 & 1,105 & 59 & 15 & 13 & 1,265 & 1,024 & 55 \\
\hline & 5.6 & 150 & 926 & 486 & 66 & 13 & 14 & 1,343 & 950 & 59 \\
\hline & 7.8 & 39 & 625 & 167 & 79 & 10 & 7 & 1,324 & 1,009 & 57 \\
\hline \multicolumn{11}{|c|}{ Bemegride $+5.0 \mathrm{mg} / \mathrm{kg}$ pentobarbital } \\
\hline \multirow[t]{7}{*}{$\mathrm{P} 257$} & Pen & 100 & 1,916 & 575 & 77 & 16 & 12 & 1,857 & 425 & 81 \\
\hline & Sal & 171 & 516 & 1,266 & 29 & 12 & 14 & 626 & 1,664 & 27 \\
\hline & 1.0 & 150 & 1,472 & 861 & 63 & 14 & 13 & 1,609 & 684 & 70 \\
\hline & 3.0 & 161 & 1,610 & 862 & 65 & 15 & 16 & 1,581 & 696 & 69 \\
\hline & 5.6 & 204 & 1,312 & 1,120 & 54 & 12 & 14 & 1,229 & 1,068 & 54 \\
\hline & 7.8 & 138 & 713 & 1,156 & 38 & 12 & 17 & 824 & 1,461 & 36 \\
\hline & 10.0 & 179 & 750 & 1,386 & 35 & 17 & 17 & 898 & 1,367 & 40 \\
\hline \multirow[t]{7}{*}{ P259 } & Pen & 200 & 2,213 & 1,252 & 64 & 14 & 14 & 1,460 & 828 & 64 \\
\hline & Sal & 198 & 869 & 2,043 & 30 & 13 & 15 & 527 & 1,754 & 23 \\
\hline & 1.0 & 270 & 3,181 & 1,266 & 72 & 17 & 15 & 1,450 & 823 & 64 \\
\hline & 3.0 & 178 & 1,682 & 1,074 & 61 & 16 & 17 & 1,446 & 823 & 64 \\
\hline & 5.6 & 274 & 2,126 & 1,846 & 54 & 13 & 16 & 1,144 & 1,141 & 50 \\
\hline & 7.8 & 263 & 1,879 & 2,154 & 47 & 16 & 16 & 932 & 1,341 & 41 \\
\hline & 10.0 & 94 & 504 & 702 & 42 & 5 & 11 & 580 & 1,757 & 25 \\
\hline P260 & Pen & 146 & 2,196 & 1,038 & 68 & 14 & 12 & 1,861 & 428 & 81 \\
\hline & Sal & 150 & 711 & 1,639 & 29 & 12 & 17 & 657 & 1,626 & 29 \\
\hline & 1.0 & 201 & 2,063 & 968 & 68 & 14 & 16 & 1,757 & 524 & 77 \\
\hline & 3.0 & 175 & 1,726 & 1,440 & 55 & 18 & 14 & 1,300 & 964 & 57 \\
\hline & 5.6 & 245 & 1,791 & 1,881 & 49 & 16 & 15 & 1,159 & 1,118 & 51 \\
\hline & 7.8 & 125 & 1,147 & 1,975 & 37 & 14 & 15 & 570 & 1,715 & 25 \\
\hline Pentobar & ital: seco & dose-r & onse de & minatior & & & & & & \\
\hline P257 & Pen & 179 & 2,623 & 950 & 73 & 17 & 14 & 1,730 & 544 & 76 \\
\hline & Sal & 131 & 749 & 1,933 & 28 & 17 & 15 & 633 & 1,634 & 28 \\
\hline & 1.0 & 146 & 940 & 1,718 & 35 & 13 & 17 & 718 & 1,564 & 31 \\
\hline & 3.0 & 169 & 1,207 & 1,600 & 43 & 17 & 16 & 962 & 1,307 & 42 \\
\hline & 5.6 & 184 & 1,579 & 1,051 & 60 & 17 & 13 & 1,384 & 897 & 61 \\
\hline & 7.8 & 199 & 2,032 & 960 & 68 & 17 & 14 & 1,535 & 742 & 67 \\
\hline & 10.0 & 72 & 1,732 & 343 & 83 & 15 & 10 & 2,080 & 219 & 90 \\
\hline & 13.0 & 50 & 1,427 & 161 & 90 & 14 & 7 & 2,199 & 118 & 95 \\
\hline
\end{tabular}


APPENDIX

(Continued)

\begin{tabular}{|c|c|c|c|c|c|c|c|c|c|c|}
\hline \multirow[b]{2}{*}{ Pigeon } & \multirow[b]{2}{*}{$\mathrm{mg} / \mathrm{kg}$} & \multirow[b]{2}{*}{ COD } & \multicolumn{3}{|c|}{ Responses } & \multicolumn{2}{|c|}{ Reinforcers } & \multicolumn{3}{|c|}{ Time } \\
\hline & & & $\mathrm{Pb}$ & $\mathbf{S}$ & $\% \mathrm{~Pb}$ & $\mathrm{~Pb}$ & $\mathbf{S}$ & $\mathrm{Pb}$ & $\mathbf{S}$ & $\% \mathrm{~Pb}$ \\
\hline \multicolumn{11}{|c|}{ Pentobarbital: second dose-response determination, continued } \\
\hline \multirow[t]{7}{*}{ P259 } & Pen & 228 & 2,547 & 1,423 & 64 & 15 & 15 & 1,486 & 791 & 65 \\
\hline & Sal & 165 & 1,157 & 2,171 & 35 & 14 & 16 & 657 & 1,620 & 29 \\
\hline & 1.0 & 222 & 1,533 & 2,048 & 43 & 14 & 17 & 995 & 1,282 & 44 \\
\hline & 3.0 & 219 & 1,740 & 2,194 & 44 & 18 & 17 & 924 & 1,337 & 41 \\
\hline & 5.6 & 254 & 2,511 & 1,101 & 70 & 16 & 18 & 1,412 & 853 & 62 \\
\hline & 7.8 & 143 & 2,580 & 1,311 & 66 & 14 & 14 & 1,547 & 742 & 68 \\
\hline & 10.0 & 249 & 2,036 & 1,450 & 58 & 13 & 14 & 1,601 & 692 & 70 \\
\hline \multirow[t]{7}{*}{ P260 } & Pen & 147 & 2,332 & 1,339 & 64 & 16 & 15 & 1,636 & 635 & 72 \\
\hline & Sal & 125 & 933 & 1,572 & 37 & 13 & 15 & 561 & 1,728 & 24 \\
\hline & 1.0 & 107 & 843 & 1,537 & 35 & 14 & 15 & 525 & 1,760 & 23 \\
\hline & 3.0 & 113 & 1,355 & 1,731 & 44 & 13 & 16 & 923 & 1,362 & 40 \\
\hline & 5.6 & 118 & 1,473 & 1,041 & 59 & 16 & 14 & 1,492 & 781 & 66 \\
\hline & 7.8 & 149 & 1,704 & 1,031 & 62 & 15 & 14 & 1,766 & 519 & 77 \\
\hline & 10.0 & 92 & 1,998 & 721 & 73 & 16 & 14 & 1,988 & 293 & 87 \\
\hline
\end{tabular}

